\title{
Reconfiguration of Handicapped Parking Spaces to Maximize Utilization of Available Space
}

\author{
Weite Lu, Upali Vandebona, and Masaru Kiyota
}

\begin{abstract}
This paper presents a design solution based on analysis of the appropriate width of handicapped parking space for individuals with different levels of disabilities in Saga. The methodology followed in this study revealed an option for increasing the available quantity of handicapped parking within the available space by selectively reducing the width of alighting space requirements built into space standards. A physical simulation was carried out with assistance from volunteers with different types of disabilities who were asked to park in a confined space in order to obtain meaningful data for space requirements by disabled individuals. The investigation found that the current standard of $3.5 \mathrm{~m}$ width adopted for handicapped parking is conservative and has little merit from the point of view of functionality for handicapped individuals. The data collected allowed the research team to develop a methodology to propose a new arrangement for increasing the parking spaces for disabled persons. The paper explains the physical data collection process and details of the proposed arrangement that could better utilize the available space.
\end{abstract}

Index Terms-Parking for disabled people, severity of disability, width of handicapped parking, alighting space, reconfiguration of parking space.

\section{INTRODUCTION}

Saga, in the island of Kyushu, is the first region in Japan to introduce a formalized handicapped parking permit identification card system (known as the PP system). This system, introduced on July 29, 2006, classified disabilities according to length of validity into two categories while broadening the definition of 'disabled person' to include non-visible disabilities, intellectual disabilities and temporary incapacitations [1]. The color of the permit conveys the length of validity [2], although many locals have come to associate the color with the level of severity of the disability.

The PP system effectively increased the population using disabled parking compared to the previous informal practice based on self-assessment of eligibility. In particular the motoring population is now aware that mild disabled including pregnant women, the elderly and those having mild trouble with walking can apply for disabled parking permits [3]. Unfortunately, the acceptance of the complete spread of disabilities in the formal system has increased the potential user population without a corresponding increase of the

Manuscript received April 28, 2014; revised June 28, 2014

Weite Lu and Masaru Kiyota are with the School of Science and Engineering, Japan (e-mail: weitelu@126.com).

Upali Vandebona is with Civil and Environmental Engineering, University of New South Wales, Australia (e-mail: u.vandebona@unsw.edu.au). number of handicapped parking spaces. Results of before and after surveys during 2006 and 2008 by Kiyota (2011) have shown that the PP system has made it harder for wheelchair bound severely disabled to find appropriate parking spaces. The percentage of severely disabled motorists observed in disabled parking spaces has decreased from $24.4 \%$ to $14.0 \%$ in a popular large shopping mall in Saga according the above surveys. [4]

There was no mechanism to increase the quantity of handicapped parking spaces to match the expansion of the disabled population that followed from the introduction of the PP system. It is difficult to change current policy in only the Saga region instead of the entirety of Japan. Drop off areas with benches for disabled passengers may resolve this problem, but not all popular shopping malls have that condition. It was hypothesized that it may be possible to add more handicapped parking spaces by a strategy of reconfiguring the disabled parking spaces according to the actual space needed by users. It was acknowledged that broad width spaces were required by wheelchair users. It was speculated however, that individuals with mild disabilities did not need the generous width of parking space provided to wheelchair users. Therefore, the suitable planning solution required may be a reconfiguration of the current overall space allocated to handicapped parking in such a manner that there are spaces with different widths to match proportions and needs of different user populations.

Experiments performed during this project showed that it is possible to establish the width of parking space used by different categories of individuals with different types of disabilities. The initial experiment surprised authors as it challenged the conventional width associated with disabled parking spaces although this paper does not propose to vary the long established standard. Following sections of the paper are presented to explain how the width of parking space required varies with the category of disability and detailed description of how the available space can be reconfigured to increase the number of spaces available for individuals with mild disabilities.

\section{Minimum Space Standards For HandicapPed PARKING IN DIFFERENT COUNTRIES}

According to legislation for disabled parking in Japan, the minimum width of handicapped parking spaces is specified as $3.50 \mathrm{~m} \mathrm{[5],} \mathrm{[6].} \mathrm{As} \mathrm{shown} \mathrm{in} \mathrm{Table} \mathrm{I,} \mathrm{the} \mathrm{value} \mathrm{adopted} \mathrm{in}$ Japan is one of the lowest among the countries investigated during the literature review. The minimum allowable width of alighting spaces is $1.40 \mathrm{~m}$ to provide sufficient room for wheelchairs to be turned around by disabled persons or caregivers [7]. It may be speculated that these low values 
have resulted because of the relatively small size of majority of vehicles [8] and body size of individuals in Japan [9]. An attempt made to uncover documentation that cover historical reasons for the genesis of the current standards in relation to disabled parking has been unsuccessful. Similarly, technical literature in Japan has not made a strict ruling on the length dimension although many countries have specified the minimum length for the disabled parking space.
The Americans with Disabilities Act (ADA) stipulations are relatively more detailed. This act even specifies blue as the color that can be used for disabled parking space markers. Minimum width for such spaces is specified as 3.96m (156 in) and the length is specified as $5.79 \mathrm{~m}$ (228 in), thereby providing the longest parking space observed during the literature survey of worldwide practice [10].

TABLE I: MINIMUM SPACE STANDARDS FOR HANDICAPPED PARKING

\begin{tabular}{c|c|c|c|c}
\hline \hline Country or Area & Width(m) & Alighting space(m) & Length(m) & Comments \\
\hline USA $^{1)}$ & 3.96 & 1.52 & 5.79 & Large value of Width and Length \\
\hline European Union $^{2)}$ & 3.60 & 1.20 & 4.80 & \\
\hline UnitedKingdom $^{3)}$ & 3.60 & 1.20 & 4.80 & Large value of Width and Length \\
\hline Australia $^{4}$ & 4.80 & 2.40 & 5.40 & Relatively small value of Width \\
\hline New Zealand $^{4)}$ & 3.50 & 1.10 & 5.00 & Relatively small value of Width \\
\hline South Korea $^{5)}$ & 3.50 & Unspecified & 5.00 & Relatively small value of Width \\
\hline Singapore $^{6)}$ & 3.60 & Unspecified & 4.80 & Unspecified \\
\hline Japan $^{7)}$ & 3.50 & 1.40 & & \\
\hline \hline
\end{tabular}

Specifications sources:

1) 2010 ADA Standards for Accessible Design; 2) The Condition of Parking Spaces Reserved for People with Disabilities in Countries that Adopted EU Model Parking Card; 3) Parking for Disabled People; 4) Parking Facilities Draft Australian/New Zealand Standard Parking facilities; 5) Guide to South Korea Disabled Vehicle Parking; 6) Code on Accessibility in the Built Environment 2007; 7) Guidelines for Development of Smooth Movement on the Road.

The European Union adopted a minimum width of $3.60 \mathrm{~m}$, a value slightly greater than the one selected in Japan. However, the minimum specified for the width of alighting area is $1.20 \mathrm{~m}$ which is somewhat lower than the value adopted in Japan. It should be noted that the European Union standards allow for two adjacent handicapped parking spaces to share a single alighting area. The length of handicapped parking spaces in off-street facilities as specified in the European Union is $4.80 \mathrm{~m}$. This is the smallest minimum length dimension observed during the literature survey. This value is shared by number of other countries as seen in Table $\mathrm{I}$, and it is almost one meter less than the corresponding value in the adopted in the USA. [11] The minimum dimensions in United Kingdom and the European Union are in agreement with each other. In United Kingdom, off-street disabled parking bays have a minimum of $4.80 \mathrm{~m}$ long and $2.40 \mathrm{~m}$ wide rectangular area allocated for the vehicle, along with an additional $1.20 \mathrm{~m}$ wide boarding and alighting space allocated when the bays are marked perpendicularly to the access aisle. Additionally, it is allowable to configure two adjacent bays sharing a common boarding area from both sides [12].

The widest minimum allowable alighting space for disabled parking has been reported in Australia and the narrowest has been reported from New Zealand as shown in Table I. As a result, the largest minimum space width for disabled parking is reported from Australia [13]. New Zealand, South Korea and Japan are among countries that adopt the smallest value for the minimum allowable parking space width at $3.5 \mathrm{~m}$. South Korean documentation indicates that width of the space specified is inclusive of the width of lane marking which can be interpreted to mean that the width per parking space can be slightly less than the minimum 3.5 $\mathrm{m}$ specified depending on the width of paint mark [14].

Specifications for handicapped parking in Singapore mention not only the dimensions but also details for the size of signs and symbols. The need for firm and level surface with adequate lighting and shelter are also mentioned. Furthermore, these standards prohibit the use of aeration slabs that can impede wheelchair movement [15].

\section{Determination of Actual Space Requirements FOR HANDICAPPED PARKING}

According to a previous questionnaire study by Kiyota [4], it is shown that $40 \%$ of wheelchair users $(n=49)$ are now inconvenienced as the population of disabled using handicapped parking has been enlarged with the acceptance of a broader definition of the term 'disability'. In a public symposium for individuals with disability held at Saga University in 2013, there was a consensus among severely disabled wheelchair users $(n=12)$ that 3.0 or $3.25 \mathrm{~m}$-wide parking spaces were sufficient size enough for them to park.

\section{A. Experiment}

With this background information, the research team aimed to find out different width requirements for different user groups according to their severity of disability. A physical simulation was performed with the aid of volunteers having different categories of disabilities to quantify the parking space requirement. The experiment involved letting the volunteer first park within a measured space and report the degree of difficulty of parking and alighting from the assigned parking space. Then the experiment was repeated, each time reducing the parking space width, until the volunteer reported it was impossible to alight. For the purpose of this experiment, a variable width parking space was designed using rubberized fabric markers placed on the ground around a parked car which is $1.79 \mathrm{~m}$-wide (silver colored) as shown in Fig.1. The volunteer cars chosen are the $1.90 \mathrm{~m}$-wide black saloon car in the photograph and $1.83 \mathrm{~m}$-wide minivan, which are two of biggest types of cars in Japan. Generally, 1.70 1.75m-wide cars are very popular in Japan because the width of municipal road $(84 \%$ in all roads in Japan) is only $3.7 \mathrm{~m}$ (two directions) [16].

The experiment was carried out in October, vehicle space is $2 \mathrm{~m}$ wide and $5 \mathrm{~m}$ long as shown in the schematic layout in Fig. 2. The alighting space (inclusive of paint mark width) indicated by the shaded area between the two vehicle spaces was initially set as $1.25 \mathrm{~m}$ wide. This equates to a parking 
space width of $3.25 \mathrm{~m}$. The $3.5 \mathrm{~m}$-wide standard handicapped parking space was not disputed by authors and therefore not subjected to test. The alighting space was then systematically reduced at steps of $0.25 \mathrm{~m}$ decrements until the minimum $0.50 \mathrm{~m}$ wide alighting space was reached by rearranging the movable floor markers of the parking space.

There were 19 volunteers (16 male and 3 female) who took part in the simulation, All of Wheelchair users $(n=12)$, crutch users $(n=1)$ and people having mild difficulties with walking $(n=4)$ are long-term disabled. Volunteers of wheelchair users (average age is 56) were invited from the organization of Spinal Injuries Japan and they have rich driving experience with an average of more than 20 years. Volunteers of crutch users, those having mild difficulties with walking (average age is 51) and pregnant women (average age is 28) participated when they knew about experiment and had interest in it. 2 people having mild difficulties with walking ( $\mathrm{P}$ and $\mathrm{Q}$ in Table II) have driving licenses but they do not drive frequently. The others ( $\mathrm{L}$ and $\mathrm{O}$ ) are good drivers with an average of 11 years of driving experience. Pregnant women ( $\mathrm{R}$ and $\mathrm{S}$ ) have rich driving experience with an average of 5 years of driving experience. Additionally, none of them were users of motorized scooters. Each volunteer was invited to park unaided at the experimental parking space and had to report the ease of the process of parking and alighting from the car without assistance from caregivers for each setting of width of the parking space. Wheelchair users were especially asked whether they can turn around in such an alighting space or not. The allowable responses in word form were: (a) No problem; (b) I can get off but a little narrow; (c) It is difficult to alight but I could do it; and (d) It is impossible to get off. The experiment begins with the widest parking space setting of $3.25 \mathrm{~m}$ as mentioned earlier. If the response was one of the first three options, then the volunteer was invited to attempt the next smaller size of the parking space. The experiment continued until the answer option (d) was selected or the minimum space width (i.e. $2.50 \mathrm{~m}$ ) had been attempted. Table II shows the complete list of volunteer responses at each of the width settings.

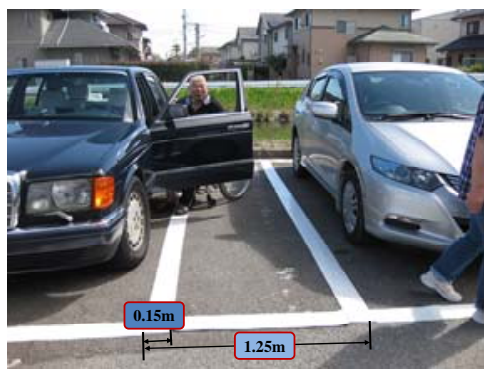

Fig. 1. The experiment site for testing width of disable parking.

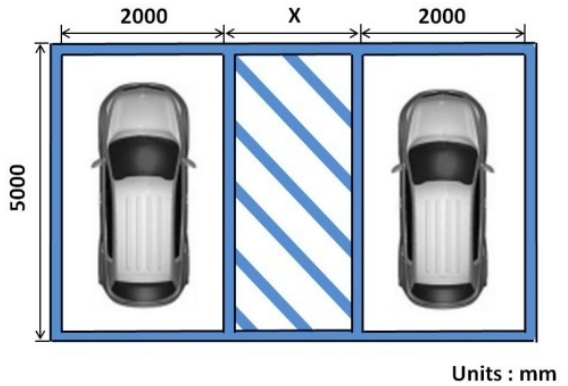

Fig. 2. Schematic arrangement for varying the width of parking space.
As Table II shows that there was no difficulty for any volunteers including wheelchair users when the width of parking space was $3.25 \mathrm{~m}$. When the width reduced to $3.00 \mathrm{~m}$, nine of the wheelchair users stated it was okay to park and alight, while one reported difficulties with using such a space. This indicates that a parking space width of $3.25 \mathrm{~m}$ is acceptable for majority of disabled users. On the other hand, width of $2.75 \mathrm{~m}$ or below is completely unacceptable for wheelchair users. However, individuals with mild disabilities and pregnant women have no difficulty with that size of parking spaces. Even $2.50 \mathrm{~m}$ width is sufficient for many such individuals, although $2.75 \mathrm{~m}$ width could be more prudent for new mothers with baby strollers.

TABLE II: DISABLED USER RESPONSES RELATED TO PARKING SPACES OF DIFFERENT WIDTHS

\begin{tabular}{|c|c|c|c|c|c|c|}
\hline \multicolumn{2}{|c|}{ The width of handicapped parking space } & $3.50 \mathrm{~m}$ & $3.25 \mathrm{~m}$ & $3.00 \mathrm{~m}$ & $2.75 \mathrm{~m}$ & $2.50 \mathrm{~m}$ \\
\hline \multirow{12}{*}{ Wheelchair users } & $\mathrm{A}$ & - & $\mathrm{a}$ & $a$ & $\mathrm{~d}$ & - \\
\hline & $\mathrm{B}$ & - & $a$ & $\mathrm{~b}$ & $\mathrm{~d}$ & - \\
\hline & $\mathrm{C}$ & - & $a$ & $\mathrm{~d}$ & - & - \\
\hline & $\mathrm{D}$ & - & $\mathrm{a}$ & $\mathrm{a}$ & $\mathrm{d}$ & - \\
\hline & $E$ & - & $\mathrm{a}$ & $\mathrm{a}$ & $\mathrm{d}$ & - \\
\hline & $\mathrm{F}$ & - & $\mathrm{a}$ & $\mathrm{a}$ & $\mathrm{d}$ & - \\
\hline & $\mathrm{G}$ & - & $a$ & $\mathrm{a}$ & $\mathrm{d}$ & - \\
\hline & $\mathrm{H}$ & - & $a$ & $\mathrm{a}$ & $\mathrm{d}$ & - \\
\hline & $\mathrm{I}$ & - & $a$ & $\mathrm{~b}$ & $\mathrm{~d}$ & - \\
\hline & $\mathrm{J}$ & - & $a$ & $a$ & $\mathrm{~d}$ & - \\
\hline & $\mathrm{K}$ & - & $a$ & $a$ & $\mathrm{~d}$ & - \\
\hline & $\mathrm{M}$ & - & $\mathrm{a}$ & $\mathrm{a}$ & $\mathrm{d}$ & - \\
\hline User of crutches & $\mathrm{N}$ & - & $a$ & $a$ & $\mathrm{c}$ & $\mathrm{d}$ \\
\hline \multirow{4}{*}{$\begin{array}{c}\text { People having mild } \\
\text { difficulties with walking }\end{array}$} & $\mathrm{L}$ & - & $a$ & $a$ & $\mathrm{a}$ & $\mathrm{b}$ \\
\hline & 0 & - & $a$ & $a$ & $\mathrm{~b}$ & $\mathrm{c}$ \\
\hline & $\mathrm{P}$ & - & $\mathrm{a}$ & $\mathrm{a}$ & $\mathrm{b}$ & $\mathrm{b}$ \\
\hline & $Q$ & - & $a$ & $\mathrm{~b}$ & $\mathrm{~b}$ & $\mathrm{c}$ \\
\hline \multirow{2}{*}{ Pregnant women } & $\mathrm{R}$ & - & $\mathrm{a}$ & $a$ & $a$ & $\mathrm{~b}$ \\
\hline & S & - & $a$ & $a$ & $a$ & $\mathrm{~b}$ \\
\hline
\end{tabular}

Note: (a) No problem. (b) I can get off but a little narrow. (c) It is difficult to alight but I could do it. (d) It is impossible to get off. (-) This setting was not attempted.

\section{B. Questionnaire Survey}

In November 2013, a follow up questionnaire survey was done with a different group of wheelchair users who were asked whether the current Japanese standard of $3.50 \mathrm{~m}$ width for handicapped parking spaces adopted from foreign standards was necessary. There were 14 wheelchair users (12 male and 2 female) who have rich driving experience more than 20 years in this study. Ten of them are more than 60 years old. $100.0 \%(n=14)$ of the sample indicated they can easily park in $3.25 \mathrm{~m}$-wide space when they go shopping in popular shopping malls. The relatively smaller average private vehicle size in

Japan may partly explain this result. [16] Anyhow, the present study has shown that there is scope to reduce the space requirement per handicapped space. This provides an opportunity to reconfigure the available space to increase the number of parking spaces. Allocation of some spaces with even smaller sizes for mildly disabled and pregnant women can further reduce the average space requirement.

There are two main findings from the physical experiment:

A space width of $3.25 \mathrm{~m}$ is sufficient for wheelchair users and those relying on crutches;

A space width of $2.75 \mathrm{~m}$ is sufficient for those with mild disabilities and pregnant women.

It is acknowledged that the sample size here is small and 
further analysis using the proposed methodology can be recommended to refine standards related to minimum width of handicapped parking spaces. It is important to note that over-specification of the width is against interests of handicapped individuals as it limits the efforts to increase the quantity of spaces.

\section{RECONFIGURATION OF HANDICAPPED PARKING SPACES}

\section{A. Basics of the Reconfiguration Concept}

According to statistical data available for 2013, the population of physically disabled people in Saga is about 41,776 , or $4.9 \%$ of the overall population [17], [18]. Also, the elderly population is about 214,997 or $25.3 \%$. In Japan, elderly is defined as one older than 65 years of age [19], and this group also may qualify for handicapped parking permits. These two groups alone form about $30 \%$ of the population although there may be some double counting in this estimate as some physically disabled are elderly as well. The estimation is further complicated because disable parking permits are also available to other individuals such as pregnant women and those having temporary difficulties due to injuries and accidents. Nonetheless, it is reasonable to consider that between $25 \%-30 \%$ of the population is eligible to use handicapped parking spaces.

Although there is a substantial legal handicapped population, the minimum required number of handicapped parking spaces in this nation is specified as $2 \%$ of the number of total parking spaces when total available spaces below 200, or $1 \%$ of the total parking spaces plus two when the 200 spaces threshold is exceeded [5,6]. This standard was established at a time when pregnant women, elderly and those having mild difficulties with walking were not considered handicapped. Thus, the number of handicapped parking spaces in Saga is inadequate to meet the demand under the PP system. However, it should be noted that the $2 \%$ recommendation is not unusual when it is considered that ADA [20] recommends only a slightly higher standard at $4 \%$ to $8 \%$ of parking spaces to be set aside for the disabled as an unmet national target in America.

A method of selectively increasing the number of parking spaces available by reducing the average width of handicapped parking spaces has been conceived and proposed in this section. This concept will be demonstrated with conditions of handicapped parking spaces in the same shopping mall previously mentioned in the introduction section.

In the proposed concept, handicapped parking spaces are divided into two types. The first type has wide handicapped parking spaces. These are effectively $3.25 \mathrm{~m}$ wide (compared to traditional use of $3.50 \mathrm{~m}$ wide spaces) and they are reserved for individuals with severe disabilities to the extent that they need wheelchairs or crutches for their mobility. The reduced value is selected based on the survey finding mentioned in the previous section. The other type has relatively narrow spaces which are effectively $2.75 \mathrm{~m}$ wide and available for all other disabled users, including pregnant women, elderly and those having mild disabilities. In this concept, severely disabled drivers are allowed to use the narrow bays if they can, but mildly disabled are not allowed to use the wide bays.
The proposed concept has a further refinement by sharing alighting space between two adjacent bays, as observed in overseas examples mentioned in Section II. This is the reason for qualifying values of width by the term 'effectively' in the previous paragraph. Fig. 3-Fig. 4 illustrate this concept by providing a comparison of traditional and proposed layouts for two adjacent handicapped parking bays. The width of two traditional handicapped spaces is $7.0 \mathrm{~m}$. In comparison, the total width of two adjacent spaces with the proposed configuration is $5.75 \mathrm{~m}$ as shown in Fig. 4, partly because only one side of the bay has the wide alighting space and partly because the alighting space width has been reduced by $0.25 \mathrm{~m}$ in agreement with the survey findings mentioned earlier.

Therefore, the average width for one handicapped parking space could be reduced to $2.875 \mathrm{~m}$, while delivering the wide space landing area in practical terms to wheelchair users. On one side of the parking bay the alighting space width is $1.25 \mathrm{~m}$ for the wheelchair users and on other side of the bay the alighting space is $0.5 \mathrm{~m}$ for able-bodied passengers and assistants. There may be some initial confusion as the driver needs to approach the parking space of the proposed system from the correct direction to orient the wheelchair user to be on the designated landing side. This means that wheelchair using drivers should approach from one direction and wheelchair using passengers should approach from the opposite direction for a particular space. The recommended approach direction alternates between adjacent parking spaces. It is acknowledged that there is a need for additional signage to guide the users with such a configuration. Also it could be worthwhile learning from the experience of overseas countries where this alternate parking practice is already allowed (see Section II).

Nevertheless, a pilot study is recommended to fully investigate operational aspects of such a configuration. Notwithstanding scope for some confusion, the proposed configuration drastically reduces the area required per disabled parking space by utilizing available space in a productive manner.

Similarly, the arrangement for parking spaces for individuals with mild disabilities can be configured to share an alighting space width of $0.75 \mathrm{~m}$, while other dimensions remain same as given in Fig.4.The average width for such a space is $2.625 \mathrm{~m}$.

\section{B. Computation of Potential Space Savings with Adoption of Proposed Configurations \\ 1) Relevant equations with the traditional handicapped parking configurations}

This section explains the underlying algebra that relates to analysis of space usage with parking spaces for disabled. Here, we will focus on three factors: the sum of widths of parking lots, the percentage of handicapped parking spaces allocated and the number of regular parking spaces in a parking complex. We will compare the traditional handicapped parking configuration against proposed configuration based on these measures.

Formulations below were developed in the context of a shopping mall parking complex where the minimum $2 \%$ handicap space rule was applicable. However, the concept could be readily extended to include larger parking could be 
readily extended to include larger parking facilities where the benefit of applying the proposed concept could be even more significant.

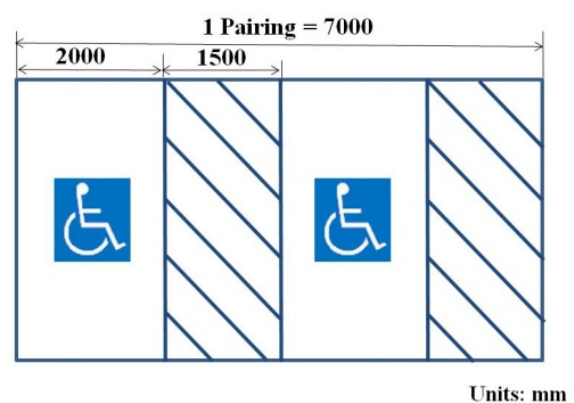

Fig. 3. Traditional handicapped parking configuration.

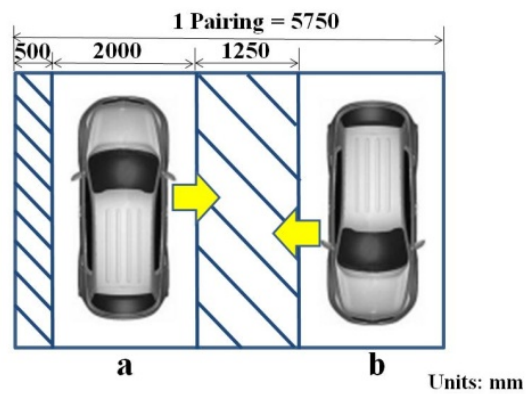

Fig. 4. Proposed handicapped parking configuration with $1.25 \mathrm{~m}$ alighting space.

Firstly, we can construct an equation for the sum of space widths of a parking lot with traditional handicapped parking configurations. It is simply the sum of widths of handicapped spaces and of all regular spaces. Therefore, the relevant formulation is as follows:

$$
S_{h}=\left[w_{h} \cdot h+w_{r} \cdot(100-h)\right] \cdot N / 100
$$

where

$S_{h}$ : Sum of widths of all parking bays with the traditional handicapped parking configuration

$w_{h}$ : The average width of one space for handicapped parking with traditional configuration (the value is $3.50 \mathrm{~m}$ )

$h$ : The percentage of handicapped parking spaces within the parking lot

$w_{r}$ : The width of one regular parking space (the value is $2.50 \mathrm{~m})$

$N$ : The total number of all parking spaces within the parking lot where handicapped parking is provided, according to the traditional configuration

Rearrangement of the above equation as shown below in (2) allows us to compute the maximum feasible number of parking spaces when the available total space width is known.

$$
N=\frac{100 \cdot S_{h}}{w_{h} \cdot h+w_{r} \cdot(100-h)}
$$

It is now possible to construct the equation to compute the number of regular parking spaces. That value can be obtained by subtracting the number of handicapped spaces from the total number as follows:

$$
N_{r}=N-N_{h}=N \cdot\left(1-\frac{h}{100}\right)
$$

where

$N_{r}$ : The number of regular parking spaces in traditional handicapped parking configuration

$N_{h}$ : The number of handicapped parking spaces in traditional handicapped parking configuration

It is now possible to rewrite the above equation by substituting Equation (2) as below:

$$
N_{r}=\frac{S_{h} \cdot(100-h)}{w_{h} \cdot h+w_{r} \cdot(100-h)}
$$

(2) and (3) can be utilized to establish the composition of disabled and regular spaces within a given lot size.

b) Equations to deal with the proposed handicapped parking configuration

For the purpose of comparing with traditional handicapped parking configurations, we now reformulate above measures using conditions of the proposed handicapped parking configuration. The method and process of formulation are similar to the method shown in the previous section.

In the proposed parking configuration, we have two types of handicapped parking spaces, one type for severe disabilities and the other for those with mild disabilities. They were earlier referred to as wide spaces and narrow spaces. Equation (4) below shows the sum of widths of the two types of handicapped parking and regular spaces.

$$
S_{h}^{\prime}=\left[w_{w} \cdot h_{w}^{\prime}+w_{n} \cdot\left(h^{\prime}-h^{\prime}{ }_{w}\right)+w_{r} \cdot\left(100-h^{\prime}\right)\right] \cdot N^{\prime} / 100
$$

where

$S_{h}^{\prime}$ : Sum of widths of all parking spaces built according to the proposed configuration

$h^{\prime}$ : The percentage of all (wide and narrow types) handicapped parking spaces

$w_{w}$ :The width of one wide space for handicapped parking (the estimated value is 2.875 as shown in IV)

$h_{w}^{\prime}$ : The percentage of wide spaces for handicapped parking

$w_{n}$ : The width of one narrow space for handicapped parking (the estimated value is 2.625 as shown in IV)

$N^{\prime}$ : The total number of parking spaces in the parking lot following proposed configuration

Then, the total number of parking spaces and the number of regular spaces are described using the same method previously mentioned for Equations (2) and (3):

$$
\begin{gathered}
N^{\prime}=\frac{100 \cdot S^{\prime}{ }_{h}}{w_{w} \cdot h^{\prime}{ }_{w}+w_{n} \cdot\left(h^{\prime}-h^{\prime}{ }_{w}\right)+w_{r} \cdot\left(100-h^{\prime}\right)} \\
N^{\prime}{ }_{r}=N^{\prime}-N^{\prime}{ }_{h}=\frac{S^{\prime}{ }_{h} \cdot\left(100-h^{\prime}\right)}{w_{w} \cdot h^{\prime}{ }_{w}+w_{n} \cdot\left(h^{\prime}-h^{\prime}{ }_{w}\right)+w_{r} \cdot\left(100-h^{\prime}\right)}
\end{gathered}
$$

$N^{\prime} r$ : The number of regular parking spaces in proposed handicapped parking configuration

$N_{h}^{\prime}$ : The number of handicapped parking spaces in proposed handicapped parking configuration

\section{2) Advantages of the proposed handicapped parking configuration}

On the basis of above equations we can compare what happens if we attempt to increase the supply of handicapped 
parking using the traditional configuration and proposed layout.

The sum of width of parking spaces is investigated first. For this purpose, consider a parking lot with 100 spaces. This means there are 2 handicapped spaces for wheelchair users and 98 regular spaces according to prevailing $2 \%$ rule in Japan. Then we will explore the impact on total space requirement with higher values for the percentage of handicap spaces. Note that (1) and (4) used for this purpose are linear functions of $h$, when other variables are known. In other words, as the percentage of handicapped parking is raised, the space requirement increases in a linear fashion. Table III shows these values computed for four different $h$ values using the measurements already mentioned. Linearity of the relationship can be readily observed there. In addition, the tabulation provides quantitative estimates for the amount of possible reduction for space requirement under the proposed configuration. There are three scenarios considered with the proposed configuration in this tabulation. The scenario 1 allocates $2 \%$ of wide space disabled parking irrespective of the $h$ value. In other words, only narrow space handicap parking is added with increase in value of $h$, after converting the initial $2 \%$ to wide space category. This means that wide spaces $=2 \%$ and narrow spaces $=28 \%$ when the $\mathrm{h}$ value is $30 \%$. The scenario 2 is an in-between option where the disabled parking is apportioned equally to the two categories. In other words when h value is $30 \%$, wide spaces $=$ narrow spaces $=15 \%$. The scenario 3 is the other extreme where all additions to handicapped parking are in wide space category. In this scenario, there is no narrow space handicapped parking added. As expected, scenario 1 provides the most reduction of space requirement at a given $h$ value, and those values are shown in the last row of the tabulation. It is noteworthy that the other scenarios also yield sum of widths of parking spaces close to scenario 1 than with the traditional configuration.

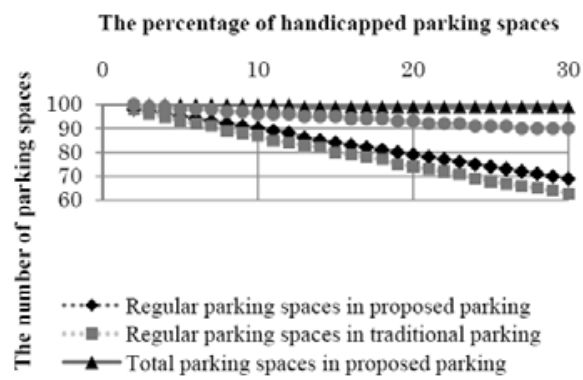

Fig. 5. Number of parking spaces possible with different percentage values of handicapped parking.

As expected, the difference in space requirement in comparison to the traditional method also varies as a linear function of $h$ (i.e. percentage of handicapped parking spaces). It can be shown that algebraic expressions formed from the difference of sum of space widths are given by $0.875 \mathrm{~h}-0.5$, $0.75 \mathrm{~h}$ and $0.625 \mathrm{~h}$ for scenarios 1,2 and 3 respectively.

Next, we can investigate the behavior of the total number of parking spaces and the number of regular spaces. For this purpose, we begin with a preset amount of area and compute the number of parking spaces that can be provided with the traditional method and proposed method. Only scenario 1 with the proposed configuration is considered to simplify the presentation. In other words, the proposed configuration considered here provides $2 \%$ wide type handicapped parking and the remainder of the handicapped parking is of the narrow type. It is convenient to assume that the preset total area is equal to $252 \mathrm{~m}$ of sum of widths, as readers have already observed that value in Table III, for total of 100 spaces under the current $2 \%$ rule.

Equations (2) and (5) provide the total number of parking spaces that can be provided in the selected total space. In Figure 5 these values are plotted after rounding down to the nearest integer to avoid reporting fractional values for parking spaces. If we consider $30 \%$ situation for the fraction of handicapped parking, the traditional method could provide only 94 spaces in total whereas the proposed method can provide 99 spaces altogether. This finding could be a significant assistance in promoting a move toward a more desirable value for $\mathrm{h}$, compared to the current $2 \%$ rule. With the proposed method, there is little reason to be alarmed about the loss of overall count of spaces. Table III has already shown the space requirement if the mall operator is adamant to maintain the total count of spaces at 100 . To ensure 100 spaces, space width of $2.25 \mathrm{~m}(=254.25-252)$ has to be added, presumably by reallocation of space previously allocated for an alternative activity.

TABLE III: COMPARISON OF SPACE REQUIREMENT

\begin{tabular}{rcccc}
\hline \hline Percentage of handicapped spaces, h & $2 \%$ & $10 \%$ & $20 \%$ & $30 \%$ \\
\hline Sum of widths of parking spaces (m) & & & & \\
Traditional configuration & 252. & 260. & 270. & 280. \\
& 00 & 00 & 00 & 00 \\
Scenario 1 & 75 & 75 & 00 & 25 \\
Proposed configuration, wide=2\%, & 250. & 251. & 253. & 254. \\
Proposed configuration, & 250. & 252. & 255. & 257. \\
wide= narrow\%, Scenario 2 & 50 & 50 & 00 & 50 \\
Scenario 3 & 75 & 75 & 50 & 25 \\
\hline Proposed configuration, narrow=0\%, & 250. & 253. & 257. & 261. \\
Traditional method value minus & 1.25 & 8.25 & 17.0 & 25.7 \\
proposed scenario 1 & & & 0 & 5 \\
\hline \hline
\end{tabular}

It may be observed that graphs in Fig. 5 appear to follow a linear pattern, if the staircase shape resulting from the rounding down is ignored. This worried the research team as the underlying equations were clearly non-linear (see (2), (3), (5) and (6)). A close examination of the calculations and the equations revealed that this is a result of magnitudes of the variables and parameters involved. It has been verified that the equations have a very little curvature at the range of values applicable here.

The number of regular parking shown in Fig. 5 is computed from (3) and (6). This is a value shop owners may focus on. There appears to be a lack of appreciation among shop owners that the official definition of handicapped covers almost $30 \%$ of the population, and those individuals are also potential customers. Nevertheless, the graphs show that the loss of regular spaces possible under higher values of $\mathrm{h}$ is less compared to an attempt to achieve such a situation while retaining traditional handicapped parking configurations.

Based on the analysis described above, there is much merit in the proposed handicapped parking configuration compared to the traditional arrangement. There is now scope to achieve a meaningful proportion of disabled parking near public facilities with minimal impact on regular users. Even if the number of regular parking spaces is not negotiable, the proposed configuration provides the least cost solution to increase disabled parking. 


\section{COnClusions And Suggestions}

An investigation of the introduction of the PP system has uncovered unintended problems caused to wheelchair users with the formalization of disabled parking arrangements. The root of the problem is the breadth of the formal definition that accepted about $30 \%$ of the population as disabled while maintaining the maximum of $2 \%$ rule as the national standard for supply quantity of disabled parking spaces. The paper looks at technical solutions available in attempts to increase the share of disabled parking and attempts to quantify impacts of such solutions on regular users of parking facilities.

This project first looked at the adequacy of the current standards for size of parking spaces assigned to wheelchair users because it was not possible to find the historical technical reasons in literature for the current practice. Experiments conducted during the project showed that the largest amount of space required by disabled persons with wheelchairs to complete the boarding and alighting processes is $0.25 \mathrm{~m}$ less than the current standard.

Opportunity to further reduce the space requirement arose with the observation that the wheelchair user does not need a space on one side and a regular landing space on the other side of the parking space as already allowed in some countries.

Next, the refinement introduced came about with the observation that much less physical parking space is needed by those with mild mobility difficulties. Therefore, the proposed scheme introduces two types of disabled parking.

The first category is referred to as wide spaces for wheelchair users and the second type is narrow in comparison provided for those with mild disabilities. The local community already thinks that the two types of disability parking permits issued reflect the severity, although the length of validity period of the permit.

The paper has presented the formulations required to analyze and understand the impact of combining the above three concepts to manage the space of a parking lot, with the intention of increasing the share of disabled parking with least impact on regular patrons. It is acknowledged that $30 \%$ of parking being devoted to disabled is an impossible target to achieve in the current socio-economic environment. A conservative target may be $20 \%$, partly to account for the possibly low mobility potential of disabled people compared to able-bodied individuals. The above value could be compared to the $4 \sim 8 \%$ recommended by ADA in the USA as the amount of parking to be allocated to vehicles of disabled.

In future research, we would like to perform our proposed model in a popular supermarket in Saga, to see what effects it brings to the handicapped users of that supermarket. From this research, we would like to gather what the users think about the new configured spaces and if it allows the supermarket users to conveniently access the shop. If the newly designed spaces make it easier and more convenient for supermarket users, we would like to try and implement a new arrangement within the Saga city government to redesign the handicapped parking spaces in parking lots in Saga. Additionally, perhaps changing the handicapped parking ratio from the current $2 \%$ to a higher percentage may give handicapped users an adequate amount of parking spaces and a happier overall experience.

\section{REFERENCES}

[1] M. Kiyota and Y. Hayashida, and A. Maeda, "Effectiveness of disabled parking identification card system without penalty and its issue," Traffic Science, vol. 40, pp. 69-76, 2009.

[2] Saga Universal Design Laboratory. (2013). Saga Prefecture. The Length of Validity for Parking Permits. [Online]. Available: http://saga-ud.jp/keikaku/machi/parkingsinsei.html.

[3] Saga Universal Design Laboratory. (2013). Saga Prefecture. Application for parking permits. [Online]. Available: http://www.pref.saga.lg.jp/web/kurashi/_1257/kf-universal-bf/_17336 .htmlb.

[4] M. Kiyota, Y. Hayashida, and A. Maeda, "Issue of disabled parking identification card system without penalty and efforts toward improving the system," Traffic Science, vol. 46, pp. 66-76, 2011.

[5] Cabinet of Japan Government, Enforcement Order of Law for Buildings Accessible to and Usable by the Elderly and Physically Disabled Persons, Japan, 1994.

[6] Ministry of Construction of Japan, "Ordinance for Enforcement of Law for Buildings Accessible to and Usable by the Elderly and Physically Disabled Persons," Ordinance of the Ministry of Construction, No.26, Japan, 1994.

[7] H. Kubota, Guidelines for Development of Smooth Movement on the Road, Japan, Taisei Press, 2008, pp. 177-178.

[8] Automobile Information Center. (2013). The Number of Light Automobiles in Japan. [Online]. Available: http://autoinfoc.com/hoyu/kokunaihoyu/hy-kokunaiihoyu-6.html

[9] Ministry of Health, Labor and Welfare. (2012). [Online]. Available: http://www.mhlw.go.jp/bunya/kenkou/eiyou/d1/h24-houkoku-05.pdf

[10] Department of Justice in U. S. (2010). [Online]. Available: http://www.ada.gov/regs2010/2010ADAStandards/2010ADAStandar ds.pdf

[11] A. Nishidate, T. Mizuno, and K. Tokuda, "The Condition of Parking Spaces Reserved for People with Disabilities in Countries that Adopted EU Model Parking Card," Memoires of the Faculty of Human Development, vol. 2, pp. 58-59, 2008.

[12] Traffic Advisory Leaflets in UK. (1995). [Online]. Available: http:// www.dft.gov.uk

[13] Australian/New Zealand Governments: Standards Australia/Standards New Zealand. Committee CE-001-Parking Facilities Draft Australian/New Zealand Standard Parking facilities. Part 6: Off-street parking for people with disabilities, Project No: 5431.2009.

[14] Korea National Institute for Special Education. (2013). [Online]. Available:

http://edu.knise.kr/jsp/lesionsee/facility/facility parking.jsp?main=4\& sub $=2$

[15] Building and Construction Authority in Singapore. (2007). [Online]. Available:

http://www.bca.gov.sg/BarrierFree/others/AccessibilityCode2007.pdf

[16] Japan Mini Vehicle Association. (2008). Why We Choose Mini Vehicle. [Online]. Available: http://www.zenkeijikyo.or.jp/pdf/kei-car2008.pdf

[17] Saga Government. (2013). The population in Saga Prefecture. Saga Statistical information. [Online]. Available: http://www.pref.saga.lg.jp/web/kensei/_1366/toukei/t-syuuki/_15639/ 52668/59639.html

[18] Statistics Japan. (2013). The Number of Certification of Physical Disability in Each Prefecture in Japan. Prefectures Grading Research Institute. [Online]. Available: http://grading.jpn.org/DivSRJ1200.html

[19] Statistics Japan. (2012). The Population of Old People more than 65 in Each Prefecture in Japan. Statistics Japan. [Online]. Available: http://www.stat.go.jp/data/jinsui/2012np/

[20] M. M. L. Ban and G. Matthew, "Handicapped Parking: A Privilege or a Right," American Journal of Physical Medicine \& Rehabilitation, vol. 89 , pp. 345-348, 2010.

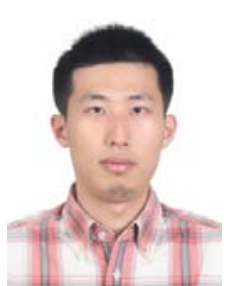

Weite Lu was born in Hangzhou, Zhejiang Province, China in 1985. He received master degree of urban and traffic design in Saga University in 2011. At present, he is a $\mathrm{PhD}$ student in the Kiyota Laboratory, Department of Civil Engineering and architecture in Saga University, Japan since 2012.

His main studies in Japan include research on the design and the traffic capacity of roundabouts, research on the handicapped parking system in Japan, research on the traffic safety policy in saga. 